\title{
A Novel Model Calculated Distribution Systems Planning Intergrated Distribution Generators for Competitive Electricity Markets
}

\author{
V. V. Thang', N. T. D. Thuy ${ }^{1}$, D. Q. Thong ${ }^{2}$, B. Q. Khanh ${ }^{2}$ \\ ${ }^{1}$ Department of Electric Power Systems, Thainguyen University of Technology (TNUT), Thainguyen, Vietnam; ${ }^{2}$ Department of \\ Electric Power Systems, Hanoi University of Science and Technology (HUST), Hanoi, Vietnam. \\ Email: thangvvhtd@tnut.edu.vn,bq_khanh-htd@mail.hut.edu.vn
}

Received 2013

\begin{abstract}
Recently, the distributed generator (DG) has been successfully studied and applied in distribution system at many countries around the world. Many planning models of the DG integrated distribution system have been proposed. These models can choose the optimization locations, capacities and technologies of DG with the objective function minimizing power loss, investment costs or total life cycle costs of the investment project. However, capacity of DG that uses renewable energy resources is natural variability according to primary energy. This study proposed a planning model of optimized distribution system that integrates DG in the competitive electricity market. Model can determine equipment sizing and timeframe requiring for upgrading equipment of distribution system as well as select DG technologies with power variable constraints of DG. The objective function is minimizing total life cycle cost of the investment project. The proposed model is calculated and tested for a 48-bus radial distribution system in the GAMS programming language.
\end{abstract}

Keywords: Competitive Electricity Markets (CEM); Distributed Generators (DG); Distribution Systems (DS) Planning

\section{Introduction}

In the past decade, distribution system planning had major changed due to the impact of competitive electricity market, DG technological development and environmental pollutions. In particular, DG connecting directly to DS or directly supplying to customers is used as a popular planning approach. These sources normally use electric generating technologies such as gas turbines, combined heat and power, Fuel Cells, solar energy and wind energies. Therefore, the benefits of DG including reduction of transmission and distribution cost, power loss and enhancement of flexibility and reliability of DS, improvement of differential voltage at nodes as well as reduction of environmental pollution [1]. However, DG requires high investment, makes increasing the complexity in measurement and relay protection as well as operation of DS [2]. Besides, DG using renewable energy resources has the naturally variable power according to primary energy.

Many planning models of the DG integrated distribution system are already been researched and proposed. The authors in [3] presented a long-term DS planning model in order to determine capacity, location and a new building investment process or to upgrade current equipments by using popular mathematical programming. The objectives of model are the minimum total of investment and operation costs of DG, the investing cost for feeder and substation transformers during planning period. The details of DG technology is not mentioned because of the assumption that the costing functions and effects of DG in DS planning are the same, but these are impossible in reality. Another model in [4] was proposed with the objective function including the total investing and operating costs of DG, feeders and substation transformers upgrading costs, energy expenses and minimum interruptible load costs. In this research, effects of DG technology are also not mentioned in selecting variables. The objective function of the two-stage DS planning model in [5] includes the minimum of total costs for upgrading feeders, substation transformers and DG construction, energy expenses purchased from market and environmental pollution costs. Similarly, [6] introduced a DS planning model determining optimized equipment sizing and timeframe required for DS upgrading. The selection issues optimal displacement, sizing, installation period and technology of DG to meet the demand growth are presented in [6]. In previous studies, the power of DG 
is always assumed to be constant without regarding to the natural variability of DG capacity which depends on the primary energy, this is not practical. Therefore, this paper proposes an optimized DS planning model that integrates output power characteristics of DG in the CEM.

The next parts of this paper are organized as follows. Section II introduces a mathematical model with objective function and constraints. Section III shows calculation results from the 48-bus DS. Conclusion is presented in Section IV

\section{The Mathematical Model}

In competitive electricity market, DS are managed by distribution companies. These companies can buy electrical energy completely from electricity market or combine with investing DG in order to meet load demands in future. So, economic and technical indices of planning project are changed which affects considerably to time, upgrading capacity of feeders and substations when DG are chosen in DS planning.

\subsection{Objective Function}

The objective function of proposed model is to minimize total life cycle cost of the investment project during calculation period as shown in Equation (1).

$$
\begin{aligned}
J & =\sum_{t}^{T} \frac{1}{(1+r)^{t}} \cdot\left(\sum_{i=1}^{N} \sum_{j=1}^{N}\left(C^{F F}+C^{F C} \cdot S^{F}{ }_{i, j, t}\right) L_{i, j}\right. \\
& +\sum_{i=1}^{N S}\left(C^{S F}+C^{S C} \cdot S^{S}{ }_{i, t}\right)^{(2)}+\sum_{i=1}^{N D G} \sum_{k=1}^{K D G} C_{k}^{D G} \cdot S_{i, k, t}^{D G}{ }^{(3)} \\
& +\sum_{i=1}^{N S} \sum_{S}^{S S} \sum_{h}^{H} k_{s}\left(k_{P} \cdot \rho_{h}^{P S} \cdot P_{i, s, t, h}^{S}+k_{Q} \cdot \rho_{h}^{Q S} \cdot Q_{i, s, t, h}^{S}\right)^{(4)} \\
& \left.+\sum_{i=1}^{N D G} \sum_{k=1}^{K D G} \sum_{s}^{S} \sum_{h}^{H} k_{s}\left(\rho_{k, h}^{P D G} \cdot P_{i, k, s, t, h}^{D G}+\rho_{k, h}^{Q D G} \cdot Q_{i, k, s, t, h}^{D G}\right)\right)^{(5)} \\
& \rightarrow M i, j \in N, k \in K D G, s \in S S, h \in H, t \in T
\end{aligned}
$$

where: Components in (1) are upgrading costs of feeders for year $t$ with fixed capital cost $\left(\mathrm{C}^{\mathrm{FF}}\right)$ and variable capital cost $\left(\mathrm{C}^{\mathrm{FC}}\right)$; Substation transformers upgrading costs in year $\mathrm{t}$ with fixed capital cost $\left(\mathrm{C}^{\mathrm{SF}}\right)$ and variable capital cost $\left(\mathrm{C}^{\mathrm{SC}}\right)$ in (2); (3) are new investment costs in year $\mathrm{t}$ with technologies $\mathrm{k}$ of DG; Electrical energy purchased cost from electricity market in (4) and (5) are fuel, operation and maintenance costs of DG depending per technology $\mathrm{k}$, operation season $\mathrm{s}$ and time $\mathrm{h} ; 1 /(1+r)^{t}$ calculated total cost at base year with discount rate $r$.

\subsection{The Constraints}

1) Contraints for nodal power balance
The output power characteristics of each DG technology using renewable energy resources fluctuate by time of day and season in year so the power of DG is also determined by each hour, season and specially, each technology $\mathrm{k}$ of DG. Therefore, constraint of nodal power balance of the model proposed in the new conditions is expressed as shown in(2).

$$
\begin{aligned}
& \sum_{k=1}^{K N G} P_{i, k, s, t, h}^{D G}+P_{i, s, t, h}^{S}-P D_{i, s, t, h} \\
= & \sum_{j=1}^{N}\left|Y_{i j, t}\right| \cdot\left|U_{i, s, t, h}\right| \cdot\left|U_{j, s, t, h}\right| \cdot \cos \left(\theta_{i j, t}-\delta_{j, s, t, h}-\delta_{i, s, t, h}\right) \\
& \sum_{k=1}^{K N G} Q_{i, k, s, t, h}^{D G}+Q_{i, s, t, h}^{S}-Q D_{i, s, t, h} \\
= & -\sum_{j=1}^{N}\left|Y_{i j, t}\right| \cdot\left|U_{i, s, t, h}\right| \cdot\left|U_{j, s, t, h}\right| \cdot \sin \left(\theta_{i j, t}-\delta_{j, s, t, h}-\delta_{i, s, t, h}\right) \\
\forall & \forall i, j \in N, k \in K D G, s \in S S, h \in H, t \in T
\end{aligned}
$$

2) Constraints of DG capacity limit

These constraints allow computed DG capacity at nodes in limit of DG technology, and it ensures annually upgrading power corresponding to equipment parameters as shown in (3).

$$
\begin{array}{ll}
0 \leq P_{i, k, t}^{D G} \leq P_{\max , k}^{D G}, & 0 \leq Q_{i, k, t}^{D G} \leq Q_{\max , k}^{D G} \\
P_{i, k, t}^{D G}=P_{i, k, t-1}^{D G}+\Delta P, & Q_{i, k, t}^{D G}=Q_{i, k, t-1}^{D G}+\Delta Q \\
t \geq 1, i \in N D G, k \in K D G &
\end{array}
$$

3) Constraints of feeders capacity limits

The feeders upgrading constraints and upgrading power satisfying equipment parameters are shown in(4).

$$
\begin{aligned}
& S_{i j, t}^{F} \geq S_{i j, 0}^{F}, S_{i j, t}^{F}=\max \left(S_{i j, s, t, h}^{F}\right), S_{i j, t}^{F} \geq\left(S_{i j, 0}^{F}+\Delta S^{F}\right) \\
& \forall t \geq 1, i, j \in N, t \in T, \forall S \in S S, h \in H
\end{aligned}
$$

4) Constraints of substation transformers capacity limits

These constraints allow to maximize the use of existing substation transformers capacity and to satisfy upgrading power corresponding to equipment parameters as(5).

$$
\begin{aligned}
& S_{i, t}^{S} \geq k_{p t} \cdot S_{i, 0}^{S}, S_{i, t}^{S}=\max \left(S_{i, s, t, h}^{S}\right), S_{i, t}^{S} \geq S_{i, t-1}^{S}+\Delta S^{S} \\
& \forall t \geq 1, i \in N S, t \in T, \forall S \in S S, h \in H
\end{aligned}
$$

5) Constraints of limited nodal voltage

Technical requirement constraints of limited nodal voltage are given in equation(6). Voltages at substation nodes are assumed constantly.

$$
\begin{aligned}
& U_{\min } \leq\left|U_{i, s, t, h}\right| \leq U_{\max } \forall i \in N L, s \in S S, t \in T, h \in H \\
& \left|U_{i, s, t, h}\right|=\text { constan } \forall i \in N S, s \in S S, t \in T, h \in H
\end{aligned}
$$

The proposed planning model is a Nonlinear Pro- 
A Novel Model Calculated Distribution Systems Planning Intergrated

Distribution Generators for Competitive Electricity Markets

gramming with Discontinuous Derivatives model and uses DNLP solver in GAMS program language [7] to find out an optimal solution with sets, indices, variables, parameters, and symbol in Table 1.

Table 1. Sets, indices, variables and parameters.

\begin{tabular}{|c|c|c|}
\hline No & Symbol & Definition \\
\hline \multicolumn{3}{|r|}{ I. Sets and Indices } \\
\hline 1 & $\mathrm{~N}$ & Set of buses in distribution system \\
\hline 2 & $i, j$ & $\operatorname{Bus}(i, j \in N)$ \\
\hline 3 & NL & Set of load buses in distribution system \\
\hline 4 & NS & Set of substation buses in distribution system \\
\hline 5 & NDG & Set of DG buses in distribution system \\
\hline 6 & $\mathrm{t}, \mathrm{T}$ & Planning year and Overall planning period \\
\hline 7 & h, H & Hour and hours per day \\
\hline 8 & k,KDG & Technology and total technology of DG $(\mathrm{k} \in \mathrm{KDG})$ \\
\hline 9 & $\mathrm{~s}, \mathrm{SS}$ & Season and total seasons in year \\
\hline \multicolumn{3}{|r|}{ II. Variables } \\
\hline 10 & $\mathrm{P}_{\mathrm{i}, \mathrm{s}, \mathrm{t}, \mathrm{h}}^{\mathrm{S}}$ & Active power purchased from electricity market \\
\hline 11 & $\mathrm{Q}_{\mathrm{i}, \mathrm{s}, \mathrm{t}, \mathrm{h}}^{\mathrm{S}}$ & Reactive power purchased from electricity market \\
\hline 12 & $\mathrm{~S}_{\mathrm{i}, \mathrm{j}, \mathrm{t}}^{\mathrm{f}}$ & Upgrading capacity of Feeder \\
\hline 13 & $\mathrm{~S}_{\mathrm{i}, \mathrm{t}}^{\mathrm{S}}$ & Upgrading capacity for Substation \\
\hline 14 & $\mathrm{~S}^{\mathrm{DG}}{ }_{\mathrm{i}, \mathrm{k}, \mathrm{t}}$ & New investment capacity of DG \\
\hline 15 & $\mathrm{P}_{\mathrm{i}, \mathrm{k}, \mathrm{s}, \mathrm{t}, \mathrm{h}}^{\mathrm{DG}}$ & Active power of DG \\
\hline 16 & $\mathrm{Q}^{\mathrm{DG}}{ }_{\mathrm{i}, \mathrm{k}, \mathrm{s}, \mathrm{t}, \mathrm{h}}$ & Reactive power of DG \\
\hline 17 & $\mathrm{U}_{\mathrm{i}, \mathrm{s}, \mathrm{t}, \mathrm{h}}$ & Voltage for bus \\
\hline 18 & $\delta_{\mathrm{i}, \mathrm{s}, \mathrm{t}, \mathrm{h}}$ & Voltage angle at bus \\
\hline \multicolumn{3}{|r|}{ III. Parameters } \\
\hline 19 & $\mathrm{r}$ & Discount rate \\
\hline 20 & $\mathrm{C}^{\mathrm{FF}}$ & Fixed capital cost of Feeder \\
\hline 21 & $\mathrm{C}^{\mathrm{FC}}$ & Variable capital cost of Feeder \\
\hline 22 & $\mathrm{~L}_{\mathrm{i}, \mathrm{j}}$ & Length of Feeder \\
\hline 23 & $\mathrm{Y}_{\mathrm{i}, \mathrm{j}, \mathrm{t}}$ & Magnitude of admittance matrix element \\
\hline 24 & $\theta_{\mathrm{i}, \mathrm{j}, \mathrm{t}}$ & Angles of admittance matrix elements \\
\hline 25 & $\mathrm{C}^{\mathrm{SF}}$ & Fixed capital cost of Substation \\
\hline 26 & $\mathrm{C}^{\mathrm{SC}}$ & Variable capital cost of Substation \\
\hline 27 & $\mathrm{C}_{\mathrm{k}}^{\mathrm{DG}}$ & New investment cost for DG technology $\mathrm{k}$ \\
\hline 28 & $\rho^{\mathrm{PS}}{ }_{\mathrm{h}}$ & Active power purchased cost from electricity market \\
\hline 29 & $\rho^{\mathrm{QS}}{ }_{\mathrm{h}}$ & Reactive power purchased cost from electricity market \\
\hline 30 & $\rho_{\mathrm{k}, \mathrm{h}}^{\mathrm{PDG}}$ & O\&M cost and Fuel cost of DG for active energy \\
\hline 31 & $\rho_{\mathrm{k}, \mathrm{h}}^{\mathrm{QDG}}$ & O\&M cost and Fuel cost of DG for reactive energy \\
\hline 32 & $\mathrm{PD}_{\mathrm{i}, \mathrm{s}, \mathrm{th} \mathrm{h}}$ & Active power demand at bus \\
\hline 33 & $\mathrm{QD}_{\mathrm{i}, \mathrm{s}, \mathrm{t}, \mathrm{h}}$ & Reactive power demand at bus \\
\hline 34 & $\mathrm{P}_{\text {max,k }}^{\mathrm{DG}}$ & Maximum DG capacity limit for active power \\
\hline 35 & $\mathrm{Q}_{\text {max,k }}^{\mathrm{DG}}$ & Maximum DG capacity limit for reactive power \\
\hline 36 & $\mathrm{U}_{\max }$ & Maximum voltage limit at bus \\
\hline 37 & $\mathrm{U}_{\min }$ & Minimum voltage limit at bus \\
\hline 38 & $\Delta \mathrm{P}$ & Active power ramp-up limit for DG in planning year \\
\hline 39 & $\Delta \mathrm{Q}$ & Reactive power ramp-up limit for DG \\
\hline 40 & $\Delta S^{S}$ & Capacity ramp-up limit for Substation transformer \\
\hline 41 & $\Delta \mathrm{S}^{\mathrm{F}}$ & Capacity ramp-up limit for Feeder \\
\hline 42 & $f_{S L}$ & Load factor of Substation transformer base year \\
\hline 43 & $\mathrm{k}_{\mathrm{P}}, \mathrm{k}_{\mathrm{Q}}$ & Variation factor of the price of electricity \\
\hline 44 & $\mathrm{k}_{\mathrm{S}}$ & Total day per season \\
\hline
\end{tabular}

\section{Results and Discussions}

\subsection{Diagram and Parameters of Distribution System}

The 38 -bus and $22 \mathrm{kV}$ voltage radial diagram is investigated in this research as Figure 1 and is connected to $110 \mathrm{kV}$ transformer substation. The total active power and reactive power at the base year are $10.85 \mathrm{MW}$ and 7.69MVAR, respectively.

\subsection{Assumptions in Analyis}

This research utilizes some economic and technical assumptions for the ease of computation:

- Planning period is 5 years and annual developing rate of load demand is constant, $11.5 \%$ per year

- The constructing cost of $110 \mathrm{kV}$ substation including fixed costs and variable costs is $0.2 \mathrm{M} \$$ and $0.05 \mathrm{M} \$ / \mathrm{MVA}$, respectively [5]. Similarly, the upgrading costs of $22 \mathrm{kV}$ feeders consist of $0.15 \mathrm{M} \$ / \mathrm{km}$ and $0.001 \mathrm{M} \$ / \mathrm{MVA} . \mathrm{km}$

- The effects of DG technology are represented by investment, operation and fuel costs. Two DG technologies, photovoltaic and small gas turbine sources, are used in this research with the corresponding capital costs to be $4.0 \mathrm{M} \$ / \mathrm{MW}$ and $0.5 \mathrm{M} \$ / \mathrm{MW}$. Average O\&M and fuel costs depend on used technology and they are assumed to be $52 \$ / \mathrm{MWh}$ and $1 \$ / \mathrm{MWh}$ for photovoltaic and small gas turbine

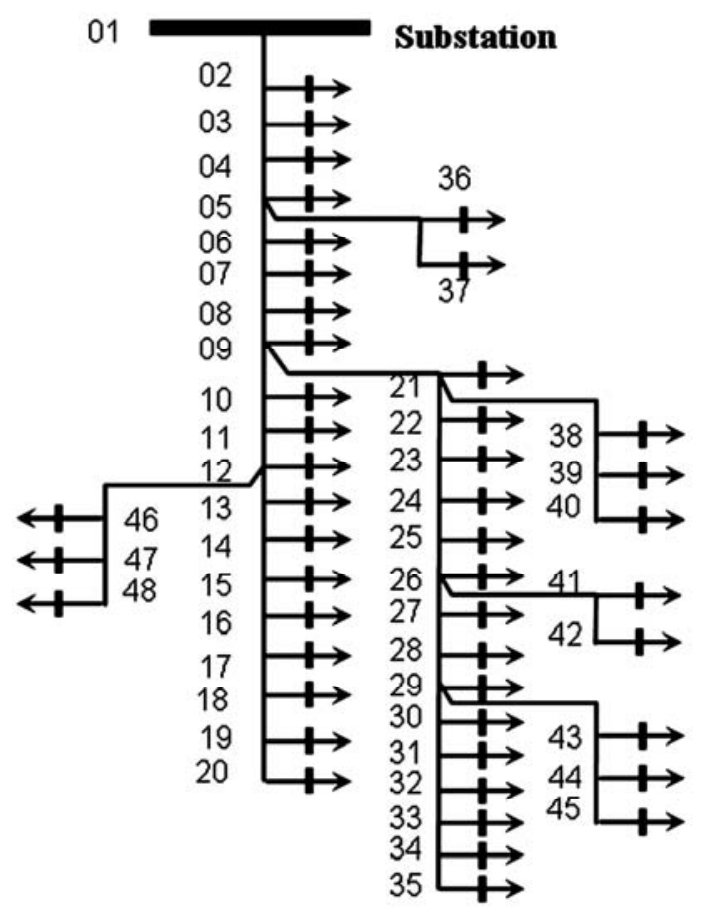

Figure 1. Diagram of radial distribution system. 
- The life of the electrical equipment is usually large and depends on manufacturing technologies such as Table 2

- Planning period is 5 years and annual developing rate of load demand is constant, $11.5 \%$ per year

- The constructing cost of $110 \mathrm{kV}$ substation including fixed costs and variable costs is $0.2 \mathrm{M} \$$ and $0.05 \mathrm{M} \$ \mathrm{MVA}$, respectively [5]. Similarly, the upgrading costs of $22 \mathrm{kV}$ feeders consist of $0.15 \mathrm{M} \$ / \mathrm{km}$ and $0.001 \mathrm{M} \$ / \mathrm{MVA} . \mathrm{km}$

- The effects of DG technology are represented by investment, operation and fuel costs. Two DG technologies, photovoltaic and small gas turbine sources, are used in this research with the corresponding capital costs to be $4.0 \mathrm{M} \$ / \mathrm{MW}$ and $0.5 \mathrm{M} \$ \mathrm{MW}$. Average O\&M and fuel costs depend on used technology and they are assumed to be $52 \$ / \mathrm{MWh}$ and $1 \$ / \mathrm{MWh}$ for photovoltaic and small gas turbine

- The life of the electrical equipment is usually large and depends on manufacturing technologies such as Table 3.

- DG is manufactured in compact modules occupying small spaces and time to install is short. Hence, installing areas at load locations are not limited

- Areas of upgrading of substation transformers and feeders are not limited

- Constraint of limited load nodes voltage changes from $0.9 \mathrm{pu}$ to $1.1 \mathrm{pu}$, and it should be $1.05 \mathrm{pu}$ at substation node

- Decided variables in the model are continuous in order to reduce the complexity of the model. Hence, they should be rounded to match real equipments.

\subsection{The Output Power Characteristics of DG}

The output power of PV depends on the intensity of solar radiation and its performance. The power of $1 \mathrm{MWp} \mathrm{PV}$ with $25 \%$ performance calculated basing on the given solar radiation intensity is presented as Figure 2.

Small gas turbines using fuel don't depend on the na- ture uncertainty of the primary energy source. Therefore, the output power characteristics of the DG are not restricted and can be operated at the requirements of load.

\subsection{Analysis Results and Disscussions}

The feasibility of the proposed model and efficiency of DG are investigated in two cases. Case A: DG is not considered when calculating DS planning. Case B: DG is integrated in the researching model.

The results of calculating showed that case A need to upgrade substation transformers with a 16MVA capacity. In contrast, investment to upgrade substation transformers in case B is deferred because of the load demand increasing in the future is provided by DG. Similarly, the case B's feeders are not also upgraded during the planning period. In the case A, 12 feeders need to upgrade in the time from $3^{\text {rd }}$ year to $5^{\text {th }}$ year as represented in Table 4.

Table 2. Lifespan of equipment.

\begin{tabular}{ccc}
\hline No & Technology & Lifespan (years) \\
\hline 1 & DG (Small gas turbine) & 20 \\
2 & DG (Photovoltaic - PV) & 30 \\
3 & Substation and Feeder & 20 \\
\hline
\end{tabular}

Table 3. Energy prices purchase from electricity market.

\begin{tabular}{cccc}
\hline Time block & Base & Intermediate & Peak \\
\hline Energy price $(\$ / \mathrm{MWh})$ & 36.35 & 58.20 & 105.95 \\
\hline
\end{tabular}

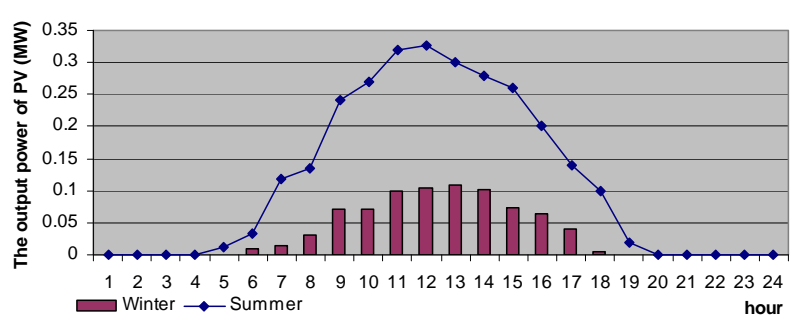

Figure 2. The output power characteristics of PV.

Table 4. Feeders Upgrading Decisions.

\begin{tabular}{|c|c|c|c|c|c|c|c|c|c|c|c|}
\hline \multirow{2}{*}{ Feeder } & \multicolumn{5}{|c|}{ Feeder section upgrading in each year $\left(\mathrm{mm}^{2}\right)$} & \multirow{2}{*}{ Feeder } & \multicolumn{5}{|c|}{ Feeder capacity upgrading in each year (MVA) } \\
\hline & 1 & 2 & 3 & 4 & 5 & & 1 & 2 & 3 & 4 & 5 \\
\hline \multicolumn{12}{|c|}{ Case A } \\
\hline $1-2$ & - & - & - & 23.24 & - & $9-21$ & - & - & 10.10 & - & - \\
\hline $2-3$ & - & - & - & 23.24 & - & $21-22$ & - & - & - & 10.10 & - \\
\hline $3-4$ & - & - & - & - & 23.24 & $22-23$ & - & - & - & - & 10.10 \\
\hline 4-5 & - & - & - & - & 23.24 & $24-25$ & - & - & - & - & 8.00 \\
\hline $5-6$ & - & - & - & - & 19.43 & $26-27$ & - & - & - & 6.67 & - \\
\hline $6-7$ & - & - & - & - & 19.43 & $27-28$ & - & - & - & - & 6.67 \\
\hline $7-8$ & - & - & - & - & 19.43 & & & & & & \\
\hline \multicolumn{12}{|c|}{ Case B } \\
\hline $\mathrm{ij}$ & - & - & - & - & - & $\mathrm{ij}$ & - & - & - & - & - \\
\hline
\end{tabular}


Table 5. DG Investment Decided.

\begin{tabular}{|c|c|c|c|c|c|c|c|c|c|c|c|c|}
\hline \multirow{2}{*}{ DG technology } & \multirow{2}{*}{ Bus } & \multicolumn{5}{|c|}{ DG capacity invested in each year (MW) } & \multirow{2}{*}{ Bus } & \multicolumn{5}{|c|}{ DG capacity invested in each year (MW) } \\
\hline & & 1 & 2 & 3 & 4 & 5 & & 1 & 2 & 3 & 4 & 5 \\
\hline Solar PV & 34 & 1.0 & - & - & - & - & 35 & 1.0 & - & - & - & - \\
\hline \multirow{4}{*}{ Gas turbine } & 19 & - & - & - & - & 0.2 & 33 & - & - & 0.3 & - & - \\
\hline & 20 & - & - & 0.2 & 0.3 & - & 34 & - & 0.1 & 0.5 & - & - \\
\hline & 31 & - & - & - & - & 0.2 & 35 & 0.1 & 0.6 & - & - & - \\
\hline & 32 & - & - & - & 0.3 & - & 45 & - & - & 0.3 & - & - \\
\hline Total & \multicolumn{12}{|c|}{$5.1 M W$} \\
\hline
\end{tabular}

Table 6. Economic Indices Comparison.

\begin{tabular}{|c|c|c|c|c|c|}
\hline \multirow{2}{*}{ No } & \multirow{2}{*}{ Cost } & \multicolumn{2}{|c|}{ Total life cycle cost (M\$) } & \multirow{2}{*}{ Comparison cost between Case B and Case A } & \multirow{2}{*}{ Note } \\
\hline & & Case A & Case B & & \\
\hline 1 & Substation Transformer upgrading & 0.19 & 0.00 & -0.19 & \multirow{5}{*}{$\begin{array}{l}\text { Total life } \\
\text { cycle cots is } \\
\text { reduced } \\
-0.37 \%\end{array}$} \\
\hline 2 & Feeder upgrading & 0.07 & 0.00 & -0.07 & \\
\hline 3 & O\&M and Electrical energy & 18.44 & 17.09 & -1.35 & \\
\hline \multirow[t]{2}{*}{4} & Investment DG & 0.00 & 1.54 & 1.54 & \\
\hline & Total & 18.66 & 18.63 & -0.07 & \\
\hline
\end{tabular}

Table 5 presents optimal investment decisions of proposed planning model for DG. The total of investment capacity during planning time is $5.1 \mathrm{MW}$ of base year's load demands. DG investment focuses mainly on the first years of planning period and selected location of DG is far from substation so high economic and technical efficiencies are gained.

Economic indices are compared between case $\mathrm{B}$ and case A as in table VI. As can be seen from the Table 6, case B holds a better economic index. Cost of DG investment and equipment upgrading (feeders and substation) are more expensive than those of case $\mathrm{A}$ about $8.23 \mathrm{M} \$$ due to a very high cost of DG investment (PV capital cost is $4.0 \mathrm{M} \$ / \mathrm{MW}$ ). However, O\&M and electric energy expenses have been decreased by $1.35 \mathrm{M} \$$ because of very low O\&M and fuel expenses of DG (PV has zero cost of fuel). Therefore, the efficiency gets higher at final years of planning period. Total life cycle cost of case B is cheaper than these of case A by $0.07 \mathrm{M} \$$, equal to $0.37 \%$.

The technical indicators of DS are also improved when DG is integrated on DS planning. The power loss at maximizing load demand times is reduced $4.35 \%$ in $5^{\text {th }}$ planning years so electric energy loss decreased 6,657.6 MWh during planning period. Total of electric energy purchased from market is also decreased $71,704.25 \mathrm{MWh}$ corresponding to $18,635.93$ tons are $\mathrm{CO}_{2}$ emission, which contributes to the decrease of environmental pollution.
The voltage loss on the feeders reduces because of DG has reduced the transmission capacity from the substation to the load. Therefore, voltage profiles at the all bus are also improved during calculation time. In particular, load node having the biggest support is 35 -bus. This bus voltage profile increased from $0.81 \mathrm{pu}$ (case A) to $0.9 \mathrm{pu}$ (case B) at $18^{\text {th }}$ hour in $5^{\text {th }}$ planning year.

\section{Conclusion}

Recently, the DS planning has been changed significantly by the impacts of CEM, DG and environmental policies. DG has many benefits for DS as enhancement of flexibility and reliability, bus voltage improvement, reduction of transmission cost and power loss as well as reduction of environmental pollution. However, the investment cost of DG is expensive and DG power that uses renewable energy resources is natural variability according to primary energy so the planning and operation calculation of DS will be more difficult. Therefore, this study proposed a new optimized DS planning model that is integrated DG in the CEM. In this model, equipment sizing and timeframe required for upgrading equipment for DS well as select DG technologies with power variable constraints of DG can be determined. The objective function is minimizing total life cycle cost of the investment project. Calculation results showed that the proposed model is suitable in large DS planning calculations and the planning together with using DG pro- 
vided better economic and technical indicators.

\section{REFERENCES}

[1] Thomas Ackermann, Go"ran Andersson, Lennart So"der, "Distributed generation: a definition", Electric Power Systems Research 57, 2001

[2] S. Wong, K. Bhattacharya and J.D.Fuller, "Comprehensive framework for long-term distribution system planning", Proc. IEEE PES Annual General Meeting, Tampa, USA, 2007

[3] Algarni, A.A.S.; Bhattacharya, K., "A Novel Approach to Disco Planning in Electricity Markets: Mathematical Model", Power Systems Conference and Exposition, 2009. PSCE '09. IEEE/PES

[4] El-Khattam, W.; Hegazy, Y.; Salama, M., “An integrated distributed generation optimization model for distribution system planning", Power Engineering Society General Meeting, IEEE, 2005

[5] S. Wong, K. Bhattacharya1and J.D. Fuller, "Electric power distribution system design and planning in a deregulated environment", IET Generation, Transmission \& Distribution, 2009

[6] V.V.Thang, D.Q.Thong, B.Q.Khanh, "A New Model Applied to the Planning of Distribution Systems for Competitive Electricity Markets", The Fourth International Conference on Electric Utility Deregulation and Restructuring and Power Technologies (DRPT) 2011, Shandong, China, 2011

[7] Richard E. Rosenthal, "GAMS - A User's Guide”, GAMS Development Corporation, Washington, USA, 2010. 